\title{
Air purification from a mixture VOCs in the pilot-scale trickle-bed bioreactor (TBB)
}

\author{
Rafał Sarzyński ${ }^{1}$, Agnieszka Gąszczak ${ }^{1}$, Daniel Janecki ${ }^{2,}{ }^{*}$, Grażyna Bartelmus ${ }^{1}$ \\ ${ }^{1}$ Institute of Chemical Engineering, Polish Academy of Sciences, ul. Bałtycka 5, 44-100 Gliwice, Poland \\ ${ }^{2}$ Department of Process Engineering, University of Opole, ul. Dmowskiego 7-9, 45-365 Opole, Poland
}

\begin{abstract}
The efficiency of the air bio-purification from the mixture of two volatile organic compounds (styrene and p-xylene) was studied. The process was carried out in a pilot-scale trickle-bed bioreactor installation designed to purify $\sim 200 \mathrm{~m}^{3} \mathrm{~h}^{-1}$ of the polluted air. The bioreactor operated at concurrent flow of gas and liquid (mineral salt solution) through packing (polypropylene Ralu rings) covered with a thin layer of microorganisms (bacterial consortium of Pseudomonas sp. E-022150 and Pseudomonas putida mt-2). The experiments, carried out for various values of a reactor load with pollutant, confirmed the great efficiency of the investigated process. At the tested bed load with pollution (inlet specific pollutant load was changed within the range of $41-84 \mathrm{gm}^{-3} \mathrm{~h}^{-1}$ ), styrene conversion degree changed within the range of 80 $87 \%$ and p-xylene conversion degree within the range of $42-48 \%$.
\end{abstract}

\section{Introduction}

Air pollution caused by human activity is an international problem since harmful substances emitted into the atmosphere are transmitted across the state borders both in the ground zone, in the rhythm of meteorological changes, and through the stratosphere. Air pollution, first of all, with volatile organic compounds (VOCs) is becoming a more and more serious problem since they are mostly toxic substances, aromatically troublesome, and they are also tropospheric ozone precursors.

There is no one universal method of air purification due to a complex chemical composition of VOCs and various process conditions. Classical physicochemical methods such as absorption, adsorption, condensation, incineration or catalytic combustion are expensive and often generate secondary pollution. Besides the above mentioned, biological methods of VOCs elimination are becoming more and more popular since they make it possible to purify big streams of air containing even very small and changeable in time amounts of harmful substances. Moreover, the bio-purification methods require the lowest financial outlay connected with VOCs utilization per $1 \mathrm{~m}^{3}$ of the purified air. By comparison, depending on the used method, the expenditure equals: 30-200 \$ - condensation, 40-190 \$ - absorption, 30-600 \$ - combustion, 25-155 \$ - adsorption and 13-90 \$ biodegradation methods [1].

It is worth noticing that biological methods of gas purification can be used only if the removed substance is biodegradable and water soluble (even slightly).

The subject of research in the presented study is the process of air bio-purification from a mixture of volatile organic compounds (styrene/ p-xylene) carried out in a pilot-scale trickle-bed bioreactor (TBB) unit. In such apparatuses the column packing is made of an inert material on which microorganisms are immobilized.

The pollution removed from the air is the only source of carbon and energy for the microorganisms. The purified air and mineral salts solution flow concurrently down the bed making it possible to use high flow rates of both phases without causing the onset of flooding in the column - a phenomenon which considerably limits the operating range of the counter-current flow. Their advantages are also both low investment and operational costs and larger potential of optimal operating parameters control.

The substances removed from the air were a mixture of styrene/p-xylene.

Styrene is one of very important raw materials for industry connected with plastics production. The world production capacity of styrene amounts to about 32.5 million tons and keeps growing by $2-3 \%$ a year on average. Such common and quantitatively large styrene consumption considerably influences the quantity of its emission into the atmosphere estimated at $25000 \mathrm{Mg}$ per year [2]. In general, the concentration of styrene in industrial waste gases may reach $1 \mathrm{gm}^{-3}$ [3] and average range varies between 0.15 and $0.4 \mathrm{gm}^{-3}$. Styrene and its metabolites are known to have serious negative effects on human health [4].

The other component of the mixture polluting the air was one of xylene isomers. Xylenes (o-, m- and pdimethylbenzene) are harmful chemicals that can be found in many consumer products such as paints, lacquers, varnishes, adhesives, inks and dyes, cleaners and degreasers, aviation gasoline, etc. They are also used

\footnotetext{
Corresponding author: zecjan@uni.opole.pl
} 
to produce a lot of plastics and synthetic fibres, insecticides and pesticides and other chemicals [5].

Crude oil and coal tar are their natural sources. Therefore, practically the total production of these substances is localized in refinery and petrochemical industry. The industrial emission of xylenes into the atmosphere is estimated at about $34000 \mathrm{Mg}$ per year in the USA, $7300 \mathrm{Mg}$ per year in Canada, out of which $58 \%$ was connected with the use of solvents and $39 \%$ with car exploitation [6]. The industrial emission of xylenes in Japan is estimated at about $48000 \mathrm{Mg}$ per year [7]. About $10-22 \%$ of the produced xylene is used for fuel enrichment. However, due to weak solubility in water and slight adsorption in soil only about $1 \%$ of xylenes introduced into the environment is to be found in water or soil, $99 \%$ goes into the atmosphere. Therefore, there is an ongoing need for the development of better treatment methods to eliminate or reduce the content of xylene in gaseous effluents prior to their release into the atmosphere. Both styrene and xylene, due to their toxic action and lowering the standard of living, were placed on the list of 189 harmful air pollutants by the US EPA (Environmental Protection Agency) - Clean Air Act 1990 [8].

In the literature one can find a lot of studies whose authors examined the process of purifying the air from styrene or xylene in biofilters using various microorganisms in the research. Experiments performed in trickle-bed bioreactors are rather limited. Extensive analysis of literature data on air biopurification from styrene/xylene was presented in our earlier papers $[9,10]$.

\section{Experimental installation experimental procedures}

and

The research into the efficiency of air purification from the mixture of styrene/xylene was carried out in a pilot installation shown schematically in Fig. 1. Its main element was a stainless steel reactor having inner diameter $1.084 \mathrm{~m}$ filled with polypropylene Ralu rings (Raschig GMBH company) $50.8 \mathrm{~mm}$ in diameter ( $\square=$ $\left.0.95 ; \mathrm{a}=110 \mathrm{~m}^{-1}\right)$. The height of the packing layer was about $1.8 \mathrm{~m}$. The biological material immobilized on packing was a mixed population of microorganisms: Pseudomonas sp. E-93486 strain showing 97\% similarity to Pseudomonas putida and $97 \%$ similarity to Pseudomonas stutzeri from 16SrRNA analysis, which does not have the ability to use xylene as a source of carbon but actively degrades styrene and Pseudomonas putida mt-2 strain degrading p-xylene. Both strains, coming from VTT Culture Collection (Finland), were carefully adapted to degrade the tested compounds and the kinetics of the bodegradation reactions was determined (tests in batch reactor).

The pilot-scale installation was automated in such a way that the control and changes of the operational parameters were possible from the operator's cabin by changing the data on the computer control screen. The following parameters were determined during the operation of the installation once a day: -styrene and p-xylene concentration in the gas stream at the inlet and outlet of the bioreactor (Varian $450 \mathrm{GC}$ chromatograph equipped with a CP-WAX 52CB column and a FID detector)

- carbon dioxide concentration in the air leaving the bioreactor (Varian 450 GC chromatograph),

- microorganism concentration in the recirculated liquid (absorbance measurement at $\lambda=550 \mathrm{~nm}$ ),

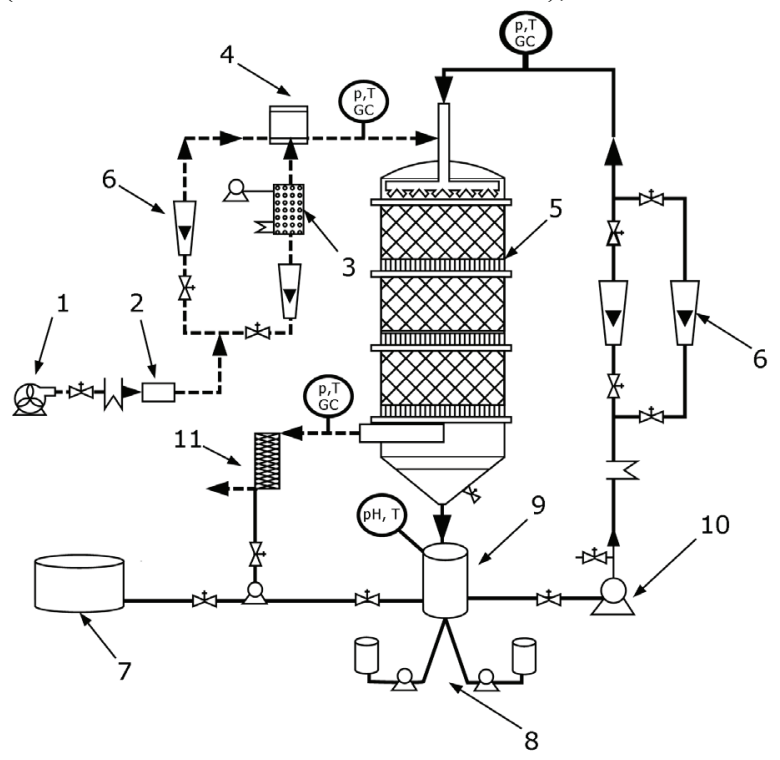

Fig. 1. Schematic diagram of experimental set-up.

- - - - gas phase, - - liquid phase, p - pressure measurememt, $\mathrm{T}$ - temperature measurement, GC - gas chromatography analysis, $\mathrm{pH}-\mathrm{pH}$ measurement

1- compressor, 2 - air filter, 3 - VOC's dosing system, 4 - gas mixing chamber, 5 - packed bioreactor, 6 - flow meter,

7- mineral salt solution container with dosing pumps, $8-\mathrm{pH}$ regulation system with dosing pumps, 9 - liquid recirculation tank, 10 - liquid pump, 11- droplet separator.

- oxygen and nitrogen concentrations in the circulating liquid (ISE max CAS40D probe and tests by $\mathrm{HACH}$ company)

- VOCs concentration in the circulating in the bioreactor installation liquid (Varian 3800 chromatograph equipped with an auto-sampler, a CP-WAX column and a FID detector).

The following were recorded 'on line' in the computer memory: flow rate of both phases, the temperature in the marked points of the installation, $\mathrm{pH}$ and the amount of the oxygen dissolved in the solution, gas pressure drop in bed, and the level of liquid in the containers.

Prior to immobilization the reactor was sterilized with water having the temperature of $95^{\circ} \mathrm{C}$ for 24 hours and next with air having the temperature of $110^{\circ} \mathrm{C}$ for 48 hours.

\section{Experimental results}

The process was carried out at optimal for bacteria strains conditions: the temperature of $30^{\circ} \mathrm{C}$ and $\mathrm{pH} 7$ maintained by batching the solutions of $\mathrm{KH}_{2} \mathrm{PO}_{4} / \mathrm{NaOH}$ according to the indications of the $\mathrm{pH}$ electrode. 
The system adapted itself to the utilized pollution with difficulty, especially to p-xylene. Only after 70 days did the bed start to operate in a stable way. During 250 days of continuous operation of the installation, out of which 70 days should be regarded as the period of bed adaptation, 6 measurement series were carried out which differed in the styrene and p-xylene concentration in the air supplied to the reactor. Volumetric flow rate of air was kept at the level of $100 \mathrm{~m}^{3} \mathrm{~h}^{-1}$ which gives the mean gas residence time in bed of $t_{g}=60 \mathrm{~s}$. The flow rate of liquid spraying the packing, which was mineral salts and microelements solution securing good condition of microorganisms immobilized on packing, was kept at the level of $8 \mathrm{~m}^{3} \mathrm{~h}^{-1}$. The composition of mineral medium was the same as given in the study [11]. The changes in styrene/p-xylene concentration in influent and effluent gas as well as conversion degree are shown in Fig. 2 and Fig. 3.

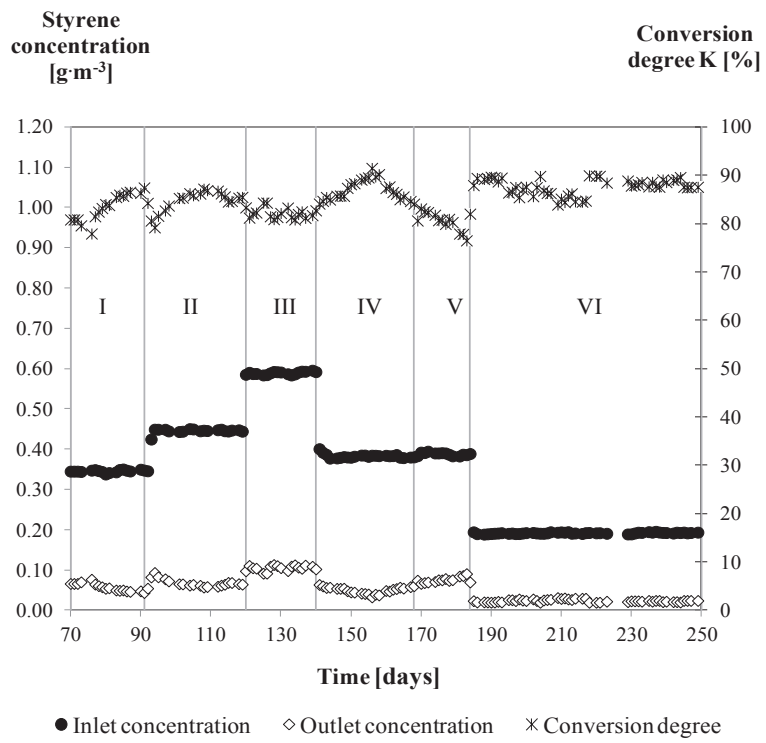

Fig. 2. Changes in the concentrations and conversion degree of styrene during the process of air purification from styrene/pxylene mixture.

The average values of inlet concentration and conversion degrees $(\mathrm{K})$ of both components for 6 series of experiments were listed in Table 1.

The conversion degrees were calculated from the dependence:

$$
K=\left(\frac{C_{g}^{0}-C_{g}^{1}}{C_{g}^{0}}\right) \cdot 100 \%
$$

where:

$\mathrm{C}_{\mathrm{g}}{ }^{0}$ and $\mathrm{C}_{\mathrm{g}}{ }^{1}$ are inlet and outlet styrene/p-xylene concentrations $\left(\mathrm{gm}^{-3}\right)$.

During the whole period of tests the styrene conversion degree was relatively high and, depending on the bed load with pollution, it varied in the range of $80-87 \%$. For p-xylene the conversion changed within the range of $42-$ $48 \%$.

The effectiveness of the process was evaluated by calculating the specific elimination capacity (EC) $\left(\mathrm{gm}^{-3} \mathrm{~h}^{-1}\right)$ defined as:

$$
E C=\frac{C_{g}^{0}-C_{g}^{1}}{t_{g}}
$$

where:

$\mathrm{t}_{\mathrm{g}}=\mathrm{V}_{\text {bed }} / \mathrm{V}_{\mathrm{g}}$ is average gas residence time ( $\mathrm{h}$ );

$\mathrm{V}_{\text {bed }}$ is bed volume $\left(\mathrm{m}^{3}\right.$ bed $)$;

$\mathrm{V}_{\mathrm{g}}$ is volumetric gas flow rate $\left(\mathrm{m}^{3} \mathrm{~h}^{-1}\right)$.

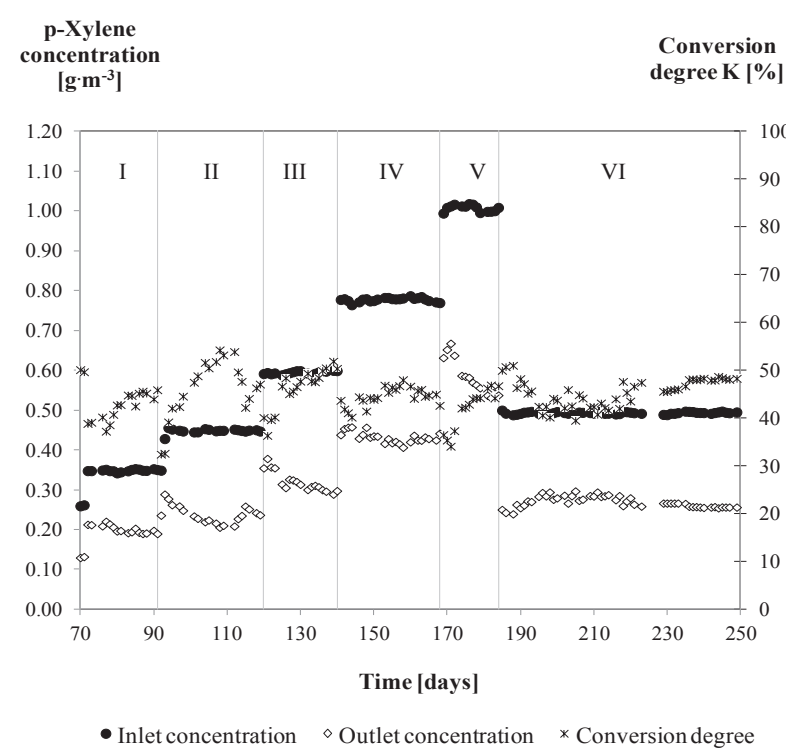

Fig. 3. Changes in the concentrations and conversion degree of $\mathrm{p}$-xylene during the process of air purification from styrene $/ \mathrm{p}$ xylene mixture.

Table 1. Average values of pollutants inlet concentrations and conversion degrees obtained in experiments (subscripts: srefers to styrene, $x$-refers to $p$-xylene).

\begin{tabular}{|c|c|c|c|c|}
\hline $\begin{array}{c}\text { No. series } \\
\text { Days }\end{array}$ & $\begin{array}{c}\mathrm{C}_{\mathrm{gs}}^{0} \\
\mathrm{~g}^{-3}\end{array}$ & $\begin{array}{c}\mathrm{C}_{\mathrm{gx}}{ }^{0} \\
\mathrm{~g}^{-3}{ }^{-3}\end{array}$ & $\begin{array}{c}\mathrm{K}_{\mathrm{s}} \\
\%\end{array}$ & $\begin{array}{c}\mathrm{K}_{\mathrm{x}} \\
\%\end{array}$ \\
\hline $\begin{array}{c}\mathbf{I} \\
\mathbf{7 0 - 9 0}\end{array}$ & 0.346 & 0.346 & 84.0 & 41.8 \\
\hline $\begin{array}{c}\text { II } \\
\mathbf{9 1 - 1 2 0}\end{array}$ & 0.447 & 0.449 & 85.0 & 47.6 \\
\hline $\begin{array}{c}\text { III } \\
\mathbf{1 2 1 - 1 4 0}\end{array}$ & 0.383 & 0.778 & 87.0 & 44.3 \\
\hline $\begin{array}{c}\text { IV } \\
\mathbf{1 4 1 - 1 6 8}\end{array}$ & 0.579 & 0.605 & 82.2 & 46.4 \\
\hline $\begin{array}{c}\mathbf{V} \\
\mathbf{1 6 9 - 1 8 3}\end{array}$ & 0.388 & 1.007 & 80.5 & 42.0 \\
\hline $\begin{array}{c}\mathbf{V I} \\
\mathbf{1 8 4 - 2 5 0}\end{array}$ & 0.191 & 0.493 & 87.1 & 44.2 \\
\hline
\end{tabular}

No clogging of the column, due to excess growth of biomass on the packing material, was observed. The changes of biofilm thickness were signalled by the increase of pressure drop in the column. After termination of each measurement series the stream of liquid spraying the bed was doubled for about $3 \mathrm{~h}$ to remove the excess biofilm.

The experimental results were plotted in Fig. 4 as a dependence of a specific elimination capacity, EC 
$\left(\mathrm{gm}^{-3} \mathrm{~h}^{-1}\right)$ vs. inlet specific pollutant load, $\mathrm{PL}^{0}\left(\mathrm{gm}^{-3} \mathrm{~h}^{-1}\right)$ which was determined from the relationship:

$$
P L^{0}=\frac{C_{g}^{0}}{t_{g}}
$$

In Fig. 4 the experimental results obtained for the air purification process from styrene only (for the same volumetric flow rates of both phases) were also presented for comparison. As it can be seen, similar styrene conversion degrees were achieved in both processes. In V series only, in which the concentration of $\mathrm{p}$-xylene in the air fed to the bioreactor was increased to $\sim 1 \mathrm{gm}^{-3}$, a systematic decrease in time of styrene conversion was observed (see Fig. 2). Therefore, fearing the poisoning of the styrene degrading strain, this measurement series was ended after 14 days.

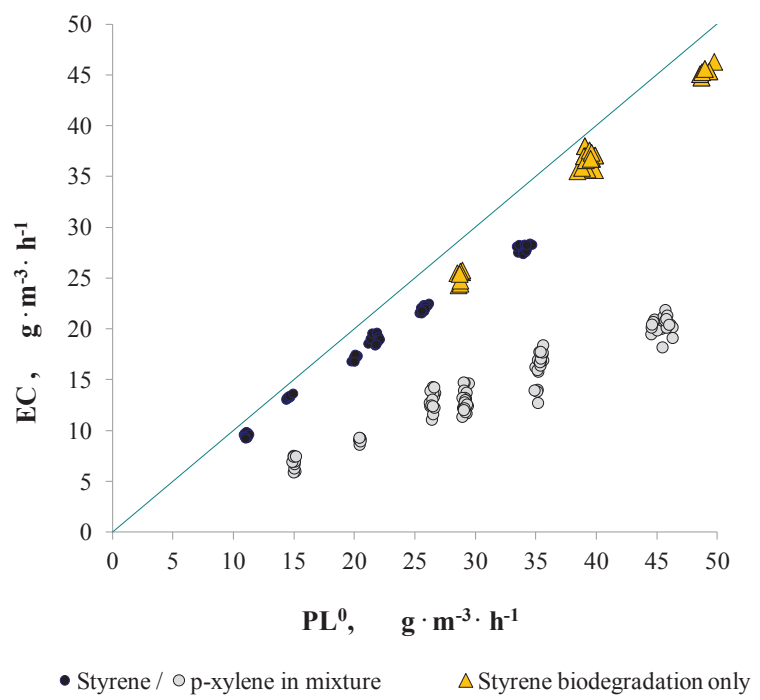

Fig. 4. Elimination capacity (EC) vs. inlet specific pollutant load $\left(\mathrm{PL}^{0}\right)$ for air purification from the mixture styrene/pxylene and from styrene only.

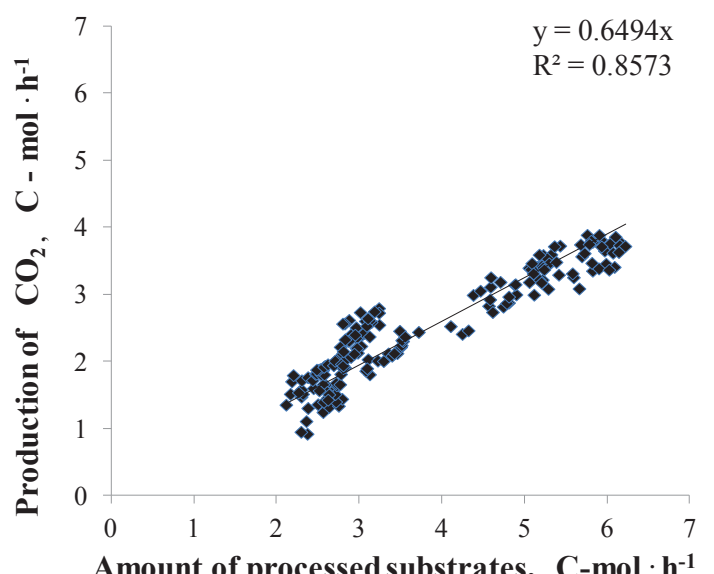

Fig. 5. Production of carbon dioxide vs. the amount of processed substrates.
In the investigated process, substrates were biodegraded in aerobic conditions to carbon dioxide, water and biomass. Hence, monitoring the carbon dioxide concentration in the gas phase can provide valuable information on the operation of the trickle-bed bioreactor. For example, the global biomass yield coefficient equaling 0.649 was calculated from the measurements of the amount of carbon dioxide produced in the process (Fig. 5).

\section{Conclusions}

The carried out research confirmed the possibility of using a trickle-bed bioreactor to purify big streams of air from a mixture of volatile organic compounds (styrene/p-xylene). At the specific pollutant load exceeding $70 \mathrm{gm}^{-3} \mathrm{~h}^{-1}$ about $2000 \mathrm{~g}$ of VOCs was removed from the air every day. The conducted experiments provided a lot of crucial information connected with conducting of the process and made it possible to work out procedures ensuring the effective and long-term operation of the installation. Moreover, the experiments showed good activity of the examined bacterial strains in the process; due to such feature the examined microorganisms may be recommended for technical application.

\section{References}

1. R. Munoz, S. Villaverde, B. Guiyesse, S. Revah, Biotechnol. Adv. 25, 410 (2007)

2. H. Jorio, L. Bibeau, M. Heitz, Environ. Sci. Technol. 34, 1764 (2000)

3. B. Bina, R. Dehghanzadeh, H. Pourmoghadas, H. Kalantary, A. Torkian, J. Res. Med. Sci. 6,280 (2004)

4. P. Vodicka, M. Koskinen, A. Naccarati, B. OeschBartlomowicz, L. Vodickova, K. Hemminki, Drug Metab. Rev. 38, 805 (2006)

5. O. Liu, A. Babajide, P. Zhu, L. Zou, Chem. Eng. Technol. 29, 320 (2006)

6. E. Elmrini, N. Bredin, Z.Shareefdeen, M. Heitz, Chem. Eng. J. 100, 149 (2004)

7. E. Jeong, M. Hirai, M. Shoda, J. Biosci. Bioeng. 102, 281 (2006)

8. J.R. Robledo-Ortiz, D. Ramirez-Arreola, A. PerezFonseca, C. Gomez, et al. , Int. Biodeter. Biodegr. 65, $539(2011)$

9. A. Gąszczak, G. Bartelmus, I. Greń, Appl. Microbiol. Biotechnol. 93, 565 (2012)

10. K. Klepacka, Prace Naukowe IICh PAN 14, 41 (2010).

11. I. Greń, A. Gąszczak,. Szczyrba, S. Łabużek, Polish J. of Environ. Stud. 18, 383 (2009) 